\title{
FSI analysis of deformation along offshore pile structure for tidal current power
}

\author{
Chul-Hee Jo $^{a}$, Do-Youb Kim ${ }^{\mathrm{a}, *}$, Yu-Ho Rho ${ }^{\mathrm{a}}$, Kang-Hee Lee ${ }^{\mathrm{a}}$, Cameron Johnstone ${ }^{\mathrm{b}}$ \\ ${ }^{a}$ Department of Naval Architecture and Ocean Engineering, Inha University, 100 Inha-ro, Nam-gu, Incheon, Republic of Korea \\ ${ }^{\mathrm{b}}$ Department of Mechanical Engineering, University of Strathclyde, Scotland, United Kingdom
}

\section{A R T I C L E I N F O}

\section{Article history:}

Received 6 February 2012

Accepted 11 July 2012

Available online 9 August 2012

\section{Keywords:}

Tidal current power (TCP)

Renewable energy

Horizontal axis turbine (HAT)

Finite element method (FEM)

Computational fluid dynamics (CFD)

Fluid-structure interaction (FSI)

\begin{abstract}
A B S T R A C T
Due to global warming, the need to secure an alternative clean energy resource has become an international issue. Tidal current power is now recognized as one of the clean power resources in Korea, where there are many strong current regions on the west and south coasts. Recently, large scale tidal devices have been deployed with a maximum rotor diameter of $18 \mathrm{~m}$. These devices impose significant loading on supporting structures. In many cases, a pile fixed foundation is used to secure the structure. However, due to the high density of seawater, the drag and lift forces are much larger than in air, causing extensive stress and deflection to the pile tower structure. In this study, a numerical analysis of the hydro-forces from a rotating tidal current turbine to a tower was conducted to determine the deformation distribution along the pile tower.
\end{abstract}

(C) 2012 Elsevier Ltd. All rights reserved.

\section{Introduction}

A tidal current power (TCP) system uses tidal current by converting kinetic energy into rotational energy to generate electricity. A turbine along the rotation axis direction can be classified into a horizontal axis turbine (HAT) and a vertical axis turbine (VAT). HAT systems are being studied worldwide [1].

Fluid-structure interaction (FSI) analysis in wind turbines is being researched actively [2], and FSI analysis of TCPs is being studied in foreign [3]. In addition, studies of composite blades with respect to TCP structural strength [4-6] and studies of large-scale turbines [7] are being performed. However, TCP tower design based on FSI is in its early stages.

Recently, TCP system capacities have become greater than $1 \mathrm{MW}$ per TCP. Turbines, which are key components of TCP system, are being designed to diameters of $18 \mathrm{~m}$. Interest in the stability evaluation of TCP structures is increasing as the structural loads increase.

In this study, a rotor was designed using blade element momentum theory, and a CFD analysis of the fluid characteristics and pressures acting on the structure was performed. The calculated pressure values were used to define loading conditions for FEM analysis, and we analyzed structural stability, deformation and stress due to tidal loads.

\footnotetext{
* Corresponding author. Tel.: +82 32860 8849; fax: +82 328645850

E-mail address: doyoubkim815@inha.edu (D.-Y. Kim).
}

\section{Rotor design}

\subsection{Determination of design current speed and turbine size}

Before determining the design current speed $\left(U_{\mathrm{D}}\right)$, a marine survey must be made of the TCP area to determine the characteristics of the current. A large turbine design based on the depth distribution of tidal current should consider the direction of the current. The size of the turbine to be installed in the ocean depths must also be considered. Turbines are now being designed to $18 \mathrm{~m}$ diameters. In this study, an $18 \mathrm{~m}$ diameter turbine was chosen and the design current speed was set to $3.5 \mathrm{~m} / \mathrm{s}$.

\subsection{Determination of output and rated revolution}

In order to estimate the output of the blade, the output coefficient $\left(C_{\mathrm{P}}\right)$, and the efficiency factors of the hydraulic power transmission gear and water tight device are substituted into Eq. (1):

$P_{\text {expect }}=\eta C_{\mathrm{P}}\left(\frac{\rho \pi D^{2} U_{\mathrm{D}}^{3}}{8}\right)$

The rated output of the blades is 2 MW. The design tip speed ratio (TSR, $\lambda_{\mathrm{D}}$ ) is 5 , and the rated rotational speed is $18.57 \mathrm{rpm}$ based on Eq. (2): 
Table 1

TCP turbine blade design parameters.

\begin{tabular}{llc}
\hline Design parameters & & Values \\
\hline$P_{\text {rated }}$ & Rated power [MW] & 2 \\
$C_{\mathrm{P}}$ & Estimated power coefficient & 0.4 \\
$U_{\text {rated }}$ & Rated current velocity [m/s] & 3.5 \\
$\rho$ & Sea water density $\left[\mathrm{kg} / \mathrm{m}^{3}\right]$ & 1025 \\
$\lambda$ & Tip speed ratio & 5 \\
$D$ & Turbine diameter [m] & 18 \\
$N$ & Blade number [EA] & 3 \\
$\omega$ & Angular speed [rpm] & 18.57 \\
\hline
\end{tabular}

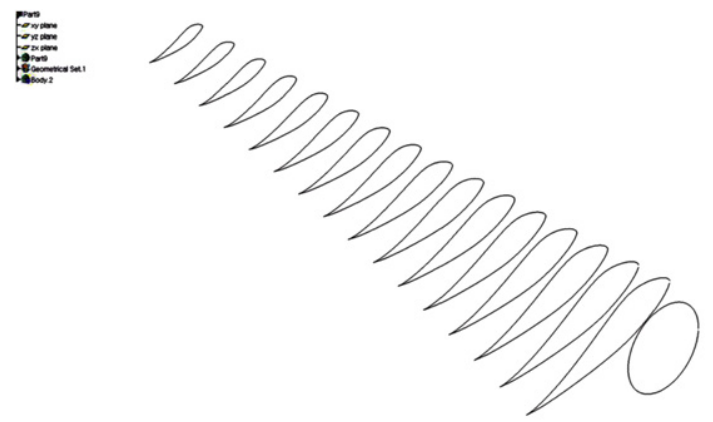

$\Delta$

$\$$

Fig. 1. Framework of 3-D TCP turbine blade model.

$N_{\mathrm{rpm}}=60\left(\frac{U_{\mathrm{D}}}{\pi D}\right) \lambda$

\subsection{Design parameters of TCP blades}

The blades were designed based on the parameters shown in Table 1 . The framework and solid modeling of the designed blade are shown in Figs. 1 and 2, respectively.

\section{TCP load calculated using CFD}

\subsection{Calculation condition}

In this study, the commercial software ANSYS WORKBENCH CFX (v13.0, ANSYS, Inc., U.S.A.) was used for three dimensional (3-D) stationary flow field analysis.

To minimize the free surface and bottom effects, the 1D clearance was considered from the tip of the turbine to the seabed and to the surface. Accordingly the TCP tower and domain height were

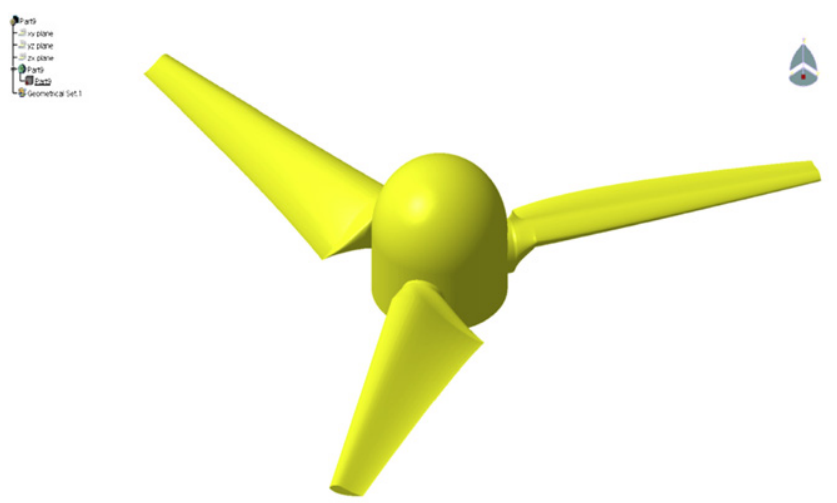

Fig. 2. Solid model of 3-D TCP turbine blade.
Table 2

Domain specification.

\begin{tabular}{lc}
\hline Description & Specification $[\mathrm{m}]$ \\
\hline Length & 216 \\
Breadth & 54 \\
Height & 54 \\
\hline
\end{tabular}

Table 3

Analysis condition

\begin{tabular}{ll}
\hline Analysis condition & Value \\
\hline Physical timescale & $0.5143 \mathrm{~s}$ \\
Residual target & $1 \mathrm{e}-05$ \\
Iteration & 586 \\
Total number of nodes & $10,354,592$ \\
Total number of elements & $13,126,871$ \\
\hline
\end{tabular}

determined as the tower height of $26.4 \mathrm{~m}$ and the depth of turbine axis $27 \mathrm{~m}$. The rear domain of the analysis has been set to be $180 \mathrm{~m}$ that is the 10 times of the turbine diameter. Specification of domain is shown in Table 2. The inner rotating domain is a cylinder which is $18.5 \mathrm{~m}$ diameter, and $3 \mathrm{~m}$ height.

\subsection{Grid systems and turbulence models}

To accurately predict the fluid characteristics, the surrounding TCP turbine and tower were modeled using a dense three-layer inflation grid. The rotating domain was composed of a dense tetrahedron grid, and a hex dominant grid was used elsewhere.

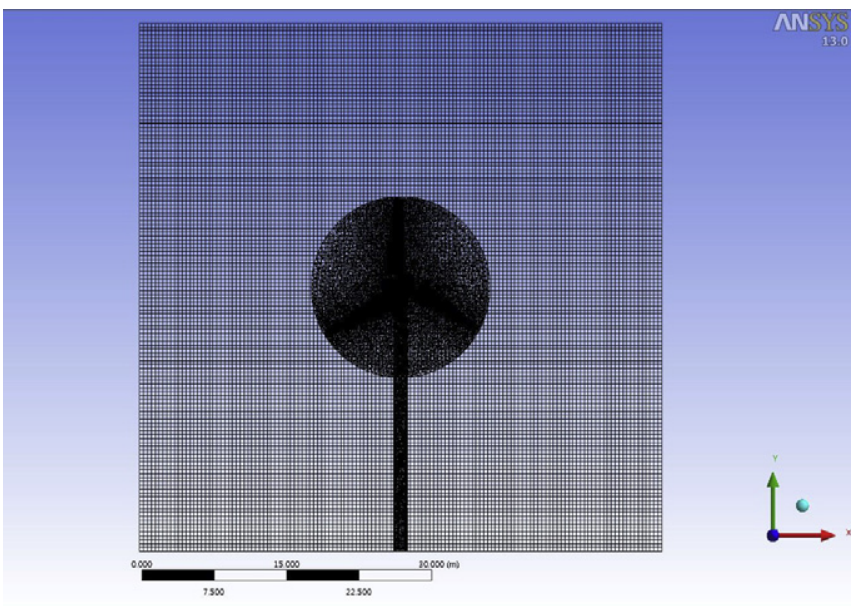

Fig. 3. Grid system of rotor and tower.

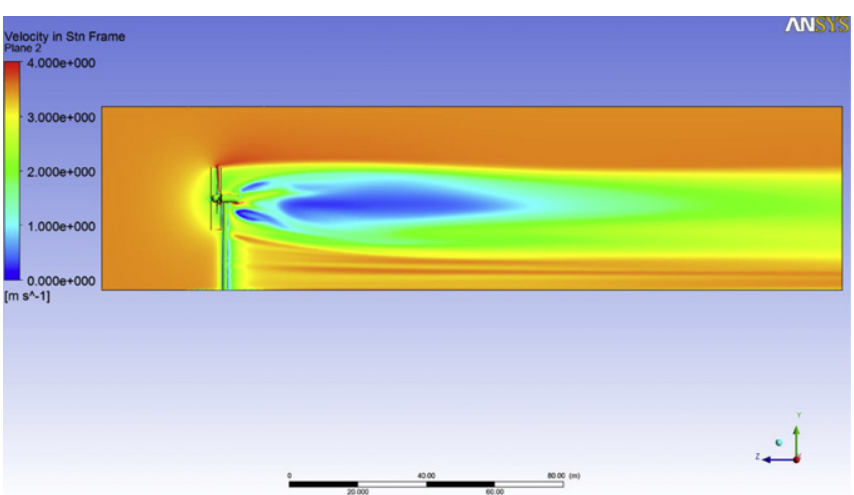

Fig. 4. Velocity distribution. 


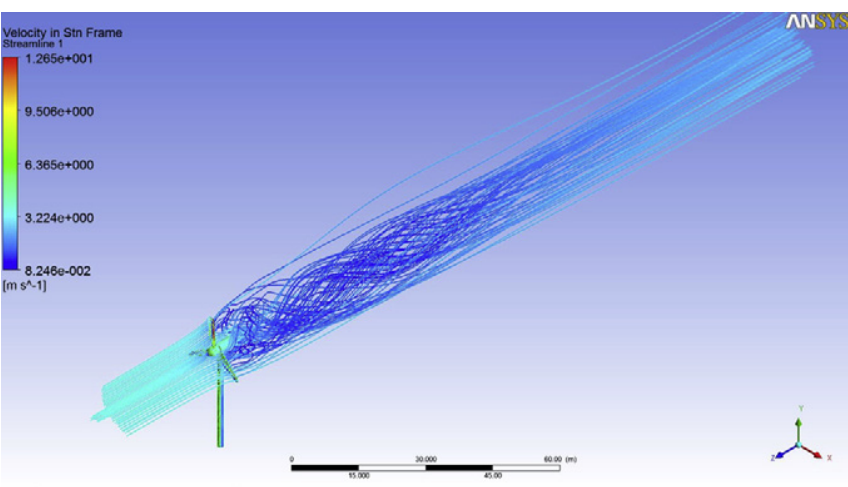

Fig. 5. Downstream streamlines.

$10,354,592$ nodes and $13,126,871$ elements were generated, as shown in Table 3 and Fig. 3.

A turbulence model that involves the dissection of the unsteady flow field around the airfoil was analyzed using the $\kappa-\omega$ shear stress transport (SST) model.

\subsection{Results of CFD analysis}

The current velocity and streamline distribution of the entire domain are shown in Figs. 4 and 5. The velocity behind the rotating turbine declined rapidly. The tidal loads pressured the entire structure, as shown in Fig. 6 . The various TCP tower diameters were investigated in the CFD analysis for $1.2,1.3,1.4$, and $1.5 \mathrm{~m}$. The tower is subjected to the external loading caused by current and rotation by turbine. As the size of tower increases, the projected area increases as well causing the larger friction and pressure forces as shown in Table 4.

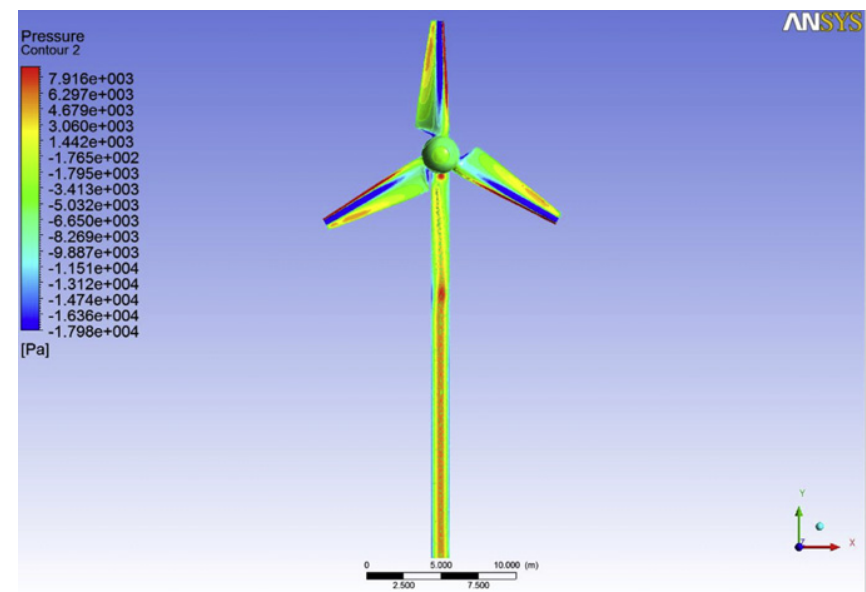

Fig. 6. Pressures along the numerical model.

Table 4

Maximum and minimum pressures on tower.

\begin{tabular}{lcl}
\hline Tower diameter $[\mathrm{m}]$ & Max $[\mathrm{Pa}]$ & Min $[\mathrm{Pa}]$ \\
\hline 1.2 & 8994.6 & -17979.2 \\
1.3 & 9239.8 & -19102.8 \\
1.4 & 10134.3 & -20300.8 \\
1.5 & 11338.5 & -21368.9 \\
\hline
\end{tabular}

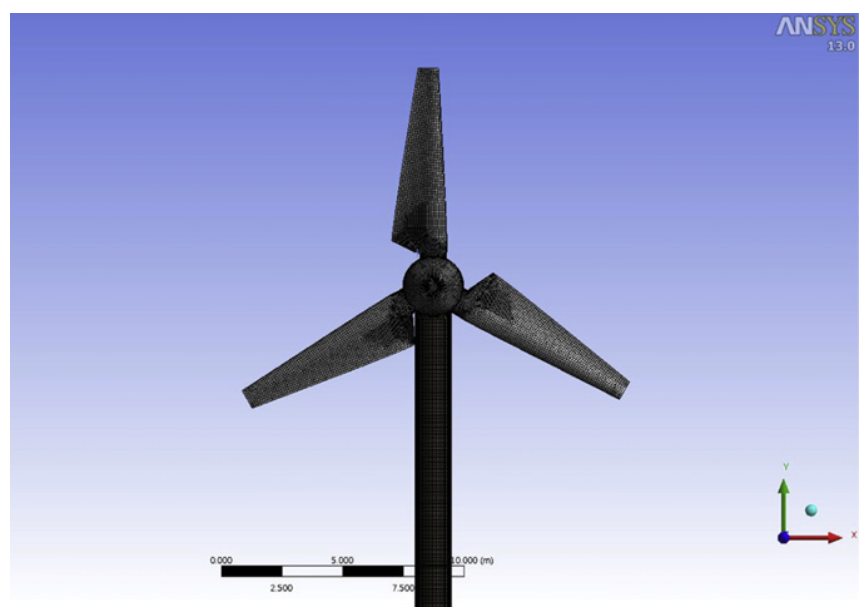

Fig. 7. Gridded TCP device with tower.

Table 5

Modeling mesh information.

\begin{tabular}{lc}
\hline Analysis condition & Value \\
\hline Blade, hub [m] & 0.08 \\
Blade-hub contact [m] & 0.04 \\
Shaft, nacelle [m] & 0.1 \\
Tower [m] & 0.05 \\
Total number of nodes & $1,310,718$ \\
Total number of elements & 190,339 \\
\hline
\end{tabular}

Table 6

Properties of materials.

\begin{tabular}{lll}
\hline Property & GFRP & API X60 \\
\hline Density $\left[\mathrm{kg} / \mathrm{m}^{3}\right]$ & 2080 & 7850 \\
Young's modulus [Pa] & $1.3 \mathrm{e}+10$ & $2 \mathrm{e}+11$ \\
Poisson's Ratio & 0.33 & 0.3 \\
Tensile yield strength $[\mathrm{Pa}]$ & $\mathrm{N} / \mathrm{A}$ & $6 \mathrm{e}+08$ \\
Compressive yield strength [Pa] & $3.1 \mathrm{e}+08$ & $\mathrm{~N} / \mathrm{A}$ \\
Tensile ultimate strength [Pa] & $5.5 \mathrm{e}+08$ & $7.5 \mathrm{e}+08$ \\
\hline
\end{tabular}

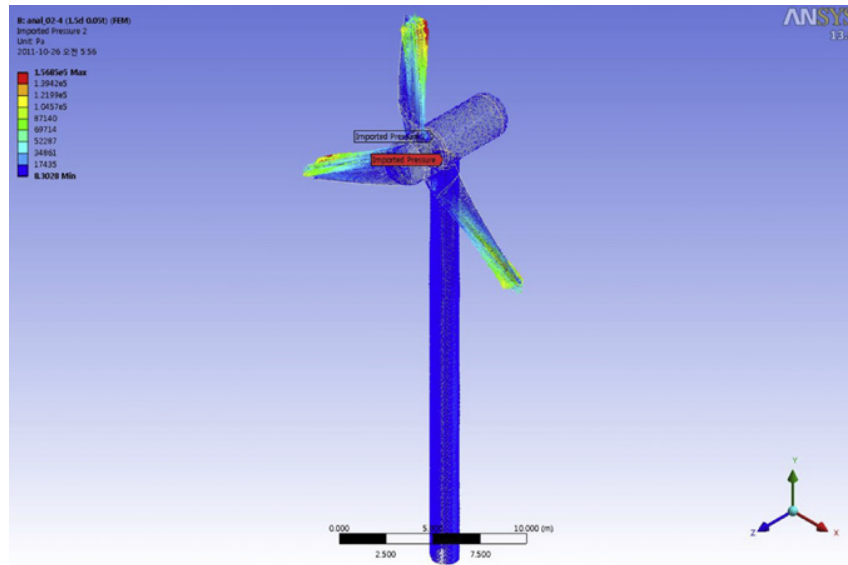

Fig. 8. Imported load due to CFD pressure. 
Table 7

Maximum stress and strain on tower.

\begin{tabular}{|c|c|c|c|c|c|c|c|c|}
\hline \multirow{2}{*}{$\frac{\text { Diameter }[\mathrm{m}]}{\text { Thickness }[\mathrm{cm}]}$} & \multicolumn{2}{|l|}{1.2} & \multicolumn{2}{|l|}{1.3} & \multicolumn{2}{|l|}{1.4} & \multicolumn{2}{|l|}{1.5} \\
\hline & Stress [MPa] & Strain $[\mathrm{m} / \mathrm{m}]$ & Stress [MPa] & Strain $[\mathrm{m} / \mathrm{m}]$ & Stress [MPa] & Strain $[\mathrm{m} / \mathrm{m}]$ & Stress [MPa] & Strain $[\mathrm{m} / \mathrm{m}]$ \\
\hline 4.0 & 924.50 & 0.0046 & & & & & & \\
\hline 4.5 & 895.30 & 0.0045 & 717.79 & 0.0036 & & & & \\
\hline 5.0 & 769.69 & 0.0038 & 654.51 & 0.0033 & 587.79 & 0.0029 & 506.09 & 0.0025 \\
\hline 5.5 & 715.46 & 0.0035 & 603.99 & 0.0030 & 524.92 & 0.0026 & & \\
\hline 6.0 & 661.68 & 0.0033 & 561.94 & 0.0028 & 487.56 & 0.0024 & & \\
\hline 6.5 & 627.56 & 0.0031 & 525.36 & 0.0026 & 455.37 & 0.0023 & & \\
\hline 7.0 & 583.10 & 0.0029 & 495.75 & 0.0025 & 427.74 & 0.0021 & & \\
\hline 7.5 & 550.72 & 0.0028 & 466.18 & 0.0023 & 403.37 & 0.0020 & & \\
\hline 8.0 & 522.44 & 0.0026 & 447.71 & 0.0022 & 384.58 & 0.0018 & & \\
\hline
\end{tabular}

Table 8

Minimum safety factors of blade and tower

\begin{tabular}{|c|c|c|c|c|c|c|c|c|}
\hline \multirow{2}{*}{$\frac{\text { Diameter }[\mathrm{m}]}{\text { Thickness [cm] }}$} & \multicolumn{2}{|l|}{1.2} & \multicolumn{2}{|l|}{1.3} & \multicolumn{2}{|l|}{1.4} & \multicolumn{2}{|l|}{1.5} \\
\hline & Blade & Tower & Blade & Tower & Blade & Tower & Blade & Tower \\
\hline 4.0 & 8.12 & 0.65 & & & & & & \\
\hline 4.5 & 7.74 & 0.67 & 7.95 & 0.84 & & & & \\
\hline 5.0 & 8.03 & 0.78 & 8.00 & 0.92 & 7.72 & 1.02 & 7.98 & 1.19 \\
\hline 5.5 & 7.74 & 0.86 & 8.00 & 1.00 & 7.96 & 1.14 & & \\
\hline 6.0 & 7.74 & 0.91 & 8.00 & 1.07 & 7.72 & 1.23 & & \\
\hline 6.5 & 7.74 & 0.97 & 8.00 & 1.14 & 7.72 & 1.32 & & \\
\hline 7.0 & 7.74 & 1.03 & 8.01 & 1.21 & 7.72 & 1.40 & & \\
\hline 7.5 & 7.74 & 1.09 & 8.01 & 1.29 & 7.72 & 1.49 & & \\
\hline 8.0 & 7.74 & 1.15 & 8.01 & 1.34 & 7.72 & 1.57 & & \\
\hline
\end{tabular}

\section{TCP structural analysis}

\subsection{Calculation conditions}

To analyze the structural stability, the fluid load from CFD result was applied to the TCP tower. The general purpose structural analysis program ANSYS WORKBENCH Static-Structural v13.0 was used.

The TCP design model used for the CFD analysis was shared for the structural study. Tower diameters of $1.2,1.3,1.4$, and $1.5 \mathrm{~m}$ were considered in the research. The thickness of the tower was complied the required standard of $D / t$ ratio that is less than 30 . The available manufacturer guideline was referenced to choose the appropriate thickness.

The pile fixed support method was applied to the TCP tower in the study with the end fixed boundary condition (Fig. 7).

\subsection{Grid systems and structure analysis}

The entire structure was composed of a hex-dominant grid. In addition to increase the accuracy, the sweep method was applied to the tower modeling. The boundary between blades and hub was closely studies by modeling $0.04 \mathrm{~m}$ fine grid. For example, the case study of $1.5 \mathrm{~m} \times 0.05 \mathrm{~m}$ tower, it has 1,310,718 nodes and 190,339 elements, as shown in Table 5.

\subsection{Material properties}

The glass fiber-reinforced plastics (GFRP) composite material for tidal current rotor and API X60 high tensile steel for the tower were applied in the analysis as shown in Table 6.

\subsection{Results of structural analysis}

In order to satisfy the recommended $D / t$ ratio for the $1.2 \mathrm{~m}$ diameter, the thickness of $0.04 \mathrm{~m}$ was chosen and the thicknesses for other towers were determined as per the same condition.

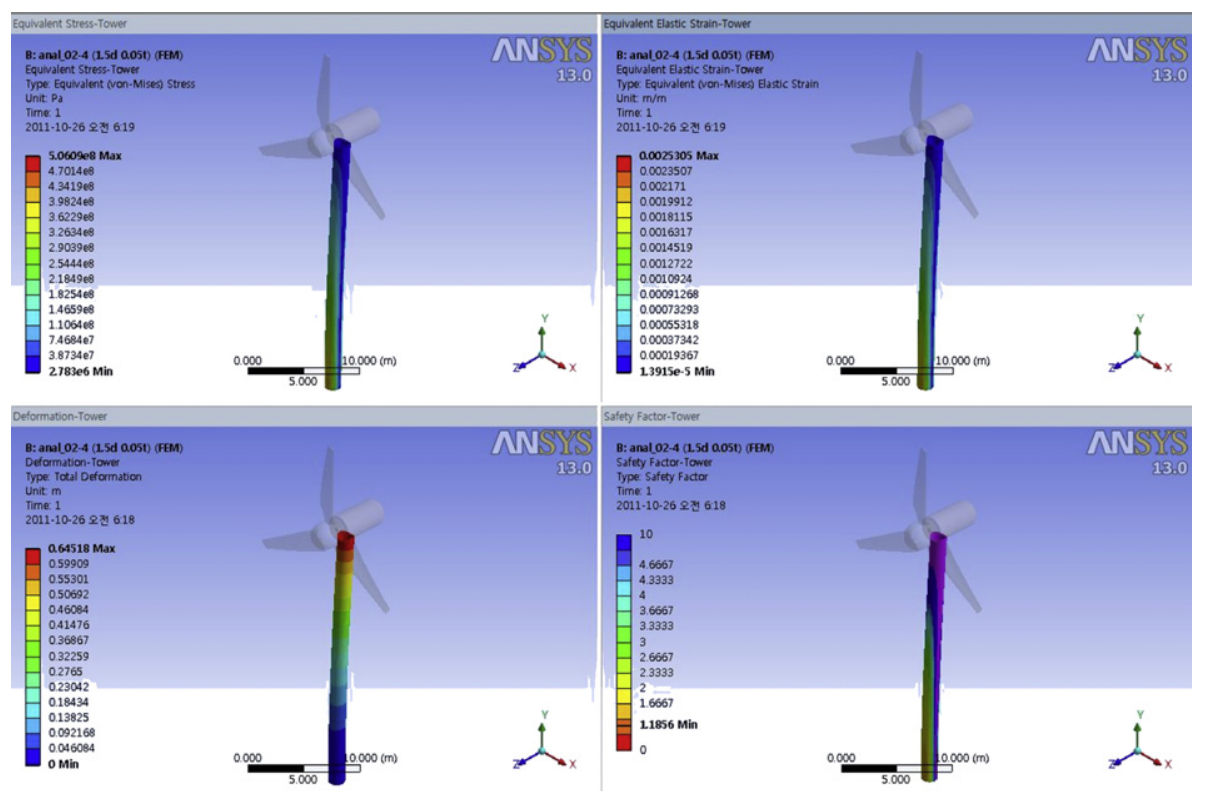

Fig. 9. Analysis results. 


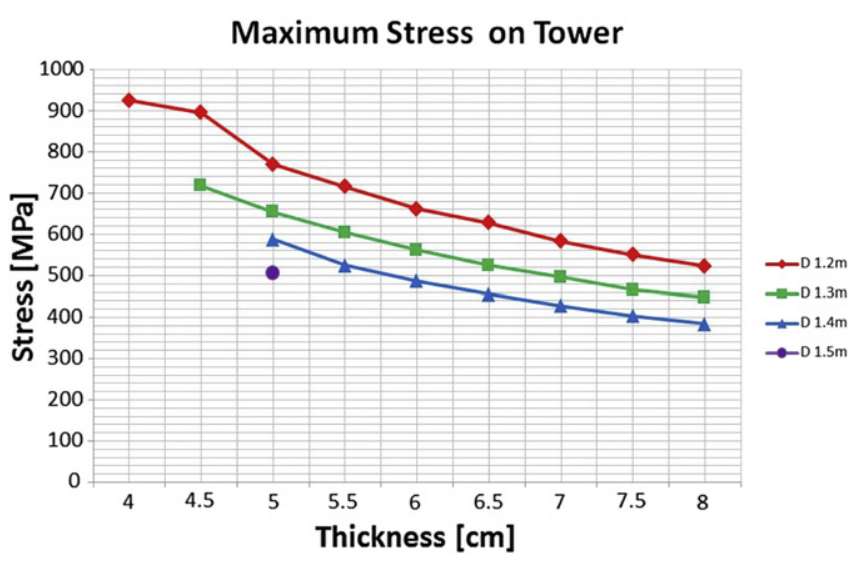

Fig. 10. Maximum stress on tower.

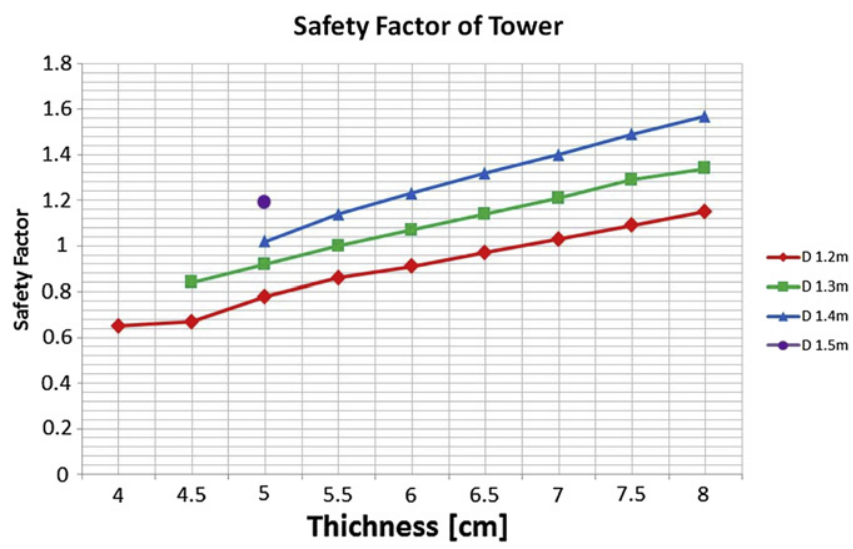

Fig. 11. Safety factor of tower.

The fluid pressure acting on the structure was obtained by CFD analysis and applied to the structural analysis as shown in Fig. 8. Tables 7 and 8 together with Fig. 9 show the stress, strain, deformation and safety factors caused by the hydro-forces. Stress and strain were calculated using the von-Mises method, and the safety factor of the material was calculated based on tensile yield strength. If the thickness of the tower is the same, the higher stress was created in the smaller diameter tower as shown in Fig. 10.
Obviously the less stress and higher s.f. were observed in the thicker towers. Figs. 10 and 11 demonstrated this observation. The minimum thicknesses that can satisfy the s.f. of 1.2 for 1.3 and $1.4 \mathrm{~m}$ towers were 7 and $6 \mathrm{~cm}$.

\section{Conclusion}

In this study, a TCP turbine was designed using blade element momentum theory and the stability was analyzed using CFD and FEM. The current speed and streamline distribution behind the rotor were confirmed, and hydro-forces acting on the TCP structure were calculated. The TCP structural stability with respect to stress, strain, deformation, and the safety factor were studied. The external and rotational loadings were applied to various TCP structure sizes. However, in the future, the vibration and transient structural analysis are to be performed to understand the better dynamic behavior and response of the offshore tidal current tower structures.

\section{Acknowledgments}

This work was supported by the Human Resources Development of the Korea Institute of Energy Technology Evaluation and Planning (KETEP) grant funded by the Korea government Ministry of Knowledge Economy (No. 20094020100070). This work is the outcome of a Manpower Development Program for Marine Energy by the Ministry of Land, Transport and Maritime Affairs (MLTM). The authors gratefully acknowledge this assistance.

\section{References}

[1] Jo CH, Kim DY, Lee KH, Rho YH, Kim KH. Design of horizontal axis tidal current power turbine with wake analysis. New \& Renewable Energy 2011;7(3): 92-100.

[2] Kim YG, Kim KC. Analysis of fluid structure interaction on 100kW-HAWT-blade. The Korean Society of Visualization 2006;4(1):41-6.

[3] Carruthers B, Marmo BA. Device modelling, simulation \& vibration analysis. International 9th European Wave and Tidal Energy Conference Series 2011.

[4] Wadia M, Meunier M, Olsen D, McEwen L. Composite blades for tidal turbines versus wind turbines at multi-megawatt scale. International 9th European Wave and Tidal Energy Conference Series 2011.

[5] Davies P, Germain G, Gaurier B, Boisseau A, Perreux D. Evaluation of the durability of composite tidal turbine blades. International 9th European Wave and Tidal Energy Conference Series 2011.

[6] Korean Register of Shipping. Technical guidelines for wind turbines. Korean Register of Shipping; 2008. p. 4-5.

[7] Kang BY, Kim YH, Kim DW, Kim MH, Han JY, Hong CH. A study of the FE analysis technique of hybrid blades for large scale wind-turbine. Journal of Ocean Engineering and Technology 2011;25(1):61-6. 